\title{
Application of Incremental Dynamic Analysis (IDA) Method for Studying the Dynamic Behavior of Structures During Earthquakes
}

\author{
Mohsen Javanpour \\ Department of Civil Engineering, \\ Dezful Branch, Islamic Azad University, Dezful, Iran
}

\author{
Panam Zarfam \\ Department of Civil Engineering, \\ Science and Research Branch, Islamic Azad University, \\ Tehran, Iran
}

\begin{abstract}
Prediction of existing buildings' vulnerability by future earthquakes is one of the most essential topics in structural engineering. Modeling steel structures is a giant step in determining the damage caused by the earthquake, as such structures are increasingly being used in constructions. Hence, two same-order steel structures with two types of structural systems were selected (coaxial moment frames and moment frame). In most cases, a specific structure needs to satisfy several functional levels. For this purpose, a method is required to determine the input request to the structures under possible earthquakes. Therefore, the Incremental Dynamic Analysis (IDA) was preferred to the Push-Over non-linear static method for the analysis and design of the considered steel structures, due its accuracy and effect of higher modes at the same time intervals. OpenSees software was used to perform accurate nonlinear analysis of the steel structure. Two parameters (spectral acceleration and maximum ground acceleration) were introduced to the modeled frames to compare the numerical correlations of seismic vulnerability obtained by two statistical methods based on the "log-normal distribution" and "logistics distribution", and finally, the parameters of displacement and drift were assessed after analysis.
\end{abstract}

Keywords-Seismic Vulnerability; Nonlinear Incremental Dynamic; moment frames; Coaxial Braced Frames

\section{INTRODUCTION}

In order to obtain a proper instruction for decreasing the impact of earthquakes, prediction of potential vulnerability of existing buildings due to future earthquakes is one of the most essential affairs in structural engineering. The design and construction should be in a way that does not lead to human loss. Common earthquakes of relatively low magnitude should not have an impact on building performance whereas a certain extent of compensated damage can be accepted in structures and equipment for earthquakes with greater magnitudes,. Steel moment frames have thus been classified into 3 categories including Special Moment-Resisting Frame (SMF), Intermediate Moment-Resisting Frame (IMF) and Ordinary Moment-Resisting Frame (OMF). These three types of systems do not have the same function. Special Moment-Resisting Frame has more ductility than Intermediate Moment-Resisting
Frame and Ordinary Moment-Resisting Frame. Hardness, ductility and strength are important parameters in seismic response of earthquake resistant structures. Although moment frames offer a very high hardness, they possess a low ductility, as in these frames usually displacement controls become dominant. Despite the moment frames, coaxial frames offer a high lateral strength and very low ductility, which brings about a very low coefficient of behavior for these frames.

Incremental dynamic analysis (IDA) is a new method to have a proper evaluation of the seismic requirements of the structure. In this method, the structure is studied under a specific set of selective earthquakes at different seismic levels. Then, usually about $16 \%, 50 \%$ and $84 \%$ of the capacity corresponding to the limiting conditions can be defined, based on the summarized curves of incremental dynamic analysis. One goal of this study is to use special features of incremental dynamic analysis for studying the dynamic behavior of structures during earthquakes. In nonlinear dynamic analysis, one or more accelerograms have been used in any analysis that each of them represents a structural response. Usually, because of the high costs of this analysis and also the long period of time required for conducting the experiments, dynamic nonlinear methods that have been designed for control of structures are applied.

The nonlinear static analysis method, in particular the Nonlinear Incremental Dynamic analysis (pushover), has the capability of evaluation of the structure behavior form elastic to plastic and final failure conditions by taking advantage form scaling the forces in different loading patterns. Considering the similarity of the transfer from the linear static analysis to Nonlinear Incremental Dynamic analysis, we can obtain the linear dynamic analysis from Nonlinear Incremental Dynamic analysis (IDA), where the seismic loading is also scaled. This concept was first introduced by Bertero in 1977 and then described in different templates [1-10]. In [11], authors prepared a detailed report about integration and the perfect introduction of Nonlinear Incremental Dynamic analysis and cleared many of the previous ambiguous concepts. Recently, IDA method was coordinated with FEMA updated instructions, which is officially used as a method for determination of the 
general collapse capacity of the structure [12]. Today, not mush studies have been conducted on the DM choices (an important parameter in the IDA analysis). This problem occurred because the studied structures are all form conventional structural buildings, as the maximum relative displacement of stairs of the overall displacement of the structure usually has two proper values of DM. For several years Pacific Earthquake Engineering Research Center (PEER) concentrated on the development of a method to evaluate the seismic performance of buildings learning [13].

In earthquake engineering based on the performance, one of the important factors is to estimate the performance of the structure under seismic loading. Thus the need for a method for estimating the parameters such as mean return period from a specific seismic requirement such a maximum displacement in stairs with one performance level such as instability caused the creation of IDA method. In reality, this method was a set of Non-linear Incremental dynamic analysis under a set of earthquake records for a specific case. In this method, the records scaled incrementally, are applied on the studied structure as finally the structure affected by overall dynamic instability. In this method first the behavior of structural components must be modeled in nonlinear form and then the records were applied on the structure and extracted the response. In this condition, the IDA curves can be described based on the response of structure to the damage in terms of intensity and vice versa. The curves, provide unique information about the nature of the structure response for several degrees of freedom. This analysis is specified for a variety of purposes, some of which include: Creating a correct understanding of structural behavior under extreme and rare earthquakes, having a better perception of changes in the nature of structure response by increasing the magnitude of earthquake (change of maximum deformation patterns at the height of structure, trend of decrease of strength and resistivity by being sensitive to the model and magnitude), obtaining estimations of the overall system dynamic capacity, studying the trend of constant or variable condition of each of the above cases for each of the records involved in the IDA analysis.

\section{SEISMIC VULNERABILITY}

"Vulnerability" is generally a term used to indicate the extent of the damage and losses that may probably occur as a result of accidents in buildings, services, geographies and in general applied to communities. According to the UNESCO's definition, the sensitivity of the environment against the occurrence and severity of a natural disaster determines its vulnerability. In [14], authors designated a general index of softening damage. Target index was based on change of the specific frequency of the first mode by reducing the hardness and resistance. By investigating the hysteresis behavior of the first modes they predicted the local and global damages. In [15], authors introduced a new way to study and measure and the concentration of damage in RC frames under the earthquake. In this method, at least one measured response was required in the case of structure and the ground acceleration. In addition, two of the lowest specific frequencies must be determined at different. Classification of damages was compared both in physical inspections and statistical tests. It was concluded that, particularly in cases where the damage is concentrated at a certain level of seismic evaluation, an appropriate assessment of the damage is achieved by using the proposed method. Seismic evaluation of a building existed in Romania was conducted in $[16,17]$, under the influence of strong earthquakes, likely for the area. Their purpose was to evaluate the appropriate modeling and analysis techniques to predict the inelastic behavior of damaged buildings vulnerable to consecutive earthquakes. The assessment was conducted using the damage indicator proposed in [18]. In [19], authors suggested a design approach based on the performance of the structure using some studies for designing against the earthquake. This means that before the designing phase, the behavior of the considered structure during the earthquake (objectives of study) were determined qualitatively and since then, some definitions were converted in quantitative form and applied as useful design information during the numerical phase. For this purpose, a method of using the concepts of energy and damage indicators was proposed.

After the earthquake of Rudbar-Manjil in Iran, evaluation of the vulnerability of buildings and studying the strengthening methods were followed strictly. For example preparation of the technical information of buildings at the Iranian Center of Opposing the Natural Disasters provided in order to deal with vulnerability of buildings and strengthening techniques. In [20], authors conducted some studies about a theoretical empirical case named the model of Iran seismic vulnerability and its sub-models besides the seismic vulnerability of Ahwaz city. In [21], authors studied the seismic vulnerability of Tehran RF bridges and the vulnerability of samples of constructed or under construction bridges and considered the qualitative aspects regarding the credit instructions of construction of bridges. In [22, 23], six reinforced concrete frames designed for gravity loads with lack of seismic resistance were studied. The results indicated that the structures showed severe weakness against the earthquake as high lateral displacement and damage of columns were observed in all of them and they were not able to tolerate the probable earthquakes in most of Iranian cities. Then, authors suggested to use cross braces to increase lateral hardness.

\section{THE INTENSITY MEASURE OF THE GROUND'S MOTION}

In order to determine the motion of the Earth at different levels of severity, from mild to very strong, it is needed to scale the selected accelerogram. For this purpose, a simple and uniform conversion has been used by scale coefficients. Scale factor (SF) in a scaled accelerogram is a non-negative numeric value (scalar) that has a range of zero to infinity which means $\lambda \in[0,+\infty)$. This numerical value is multiplied in all values recorded from considered accelerogram and regarding being less, more or equal to 1 , the intensity level is reduced or increased. $\alpha_{\lambda}=\lambda \alpha_{1}$ where, $\alpha_{\lambda}$ is the scaled accelerogram vector and $\mathrm{a} 1$ is the non-scaled accelerogram vector.

The Intensity Measure of the ground's motion (IM) is a scaling quantity of an accelerogram. This quantity is a function of the original accelerogram which varies according to the increase or decrease in the accelerogram: 


$$
\mathrm{IM}=f\left(a_{1}(\lambda)\right)
$$

Examples of such quantity that can be scaled include: Peak ground acceleration (PGA), Peak Ground Velocity (PGV), Spectral Acceleration (SA) in vibrating mode of structures taking into account the Damage Measure, $\mathrm{Sa}\left(\mathrm{T}_{\mathrm{i}}, \xi \%\right)$.

\section{DAMAGE MEASURE OR VARIABILITY OF STRUCTURES}

Damage Measure or the variability of structure variability (DM) is a positive numeric value that describes the response properties of structural models against seismic loads or in other words, it is the excess reaction of structural model due to loading. This quantity is a non-negative numerical value (scalar) that has a range of zero to infinity, where $\mathrm{DM} \in[0,+\infty)$.

\section{CURVES OF INCREMENTAL NON-LINEAR DYNAMIC ANALYSIS}

Incremental non-linear dynamic analysis curves include of some (IDA) curves, as each of them are obtained using several nonlinear dynamic analysis on a accelerogram scaled at some magnitude level.

\section{THE INTRODUCTION OF STUDIED FRAMEWORKS}

Frameworks under consideration include the mean steel moment frames and steel coaxial braced frames (Cross). Both frames consist of 6 floors (including the roof, 7 stair levels) and 5 openings. Floors heights were 3 meters and length of each opening was considered to be 4 meters. It is worth noting that the width of load-bearing of the roofs was also 4 meters. Seismic loading was based on the Fourth Edition of Iranian 2800 instruction and gravitational loading was also performed based on the sixth issue of national building regulations. The following characteristics have been used for determining the seismic parameters of frames: Residential application $(\mathrm{I}=1)$, Tehran area with very high risk $(\mathrm{A}=0.35)$, average steel moment frame $\left(R_{1}=7\right)$, coaxial braced steel frame $\left(R_{2}=6\right)$ and soil of zone III. According to paragraph 3.2.2 of Regulations of Designing buildings against earthquakes (2800 instruction), Fourth Edition), equivalent static analysis can be applied in three-storey and shorter buildings, from the ground state or the following buildings:

- Regular buildings with a height of less than 50 meters from the base level.

- Irregular buildings with a height less than 50 meters from the base level that has: High and extreme torsional irregularity is not exited in the plan.

No mass, soft and very soft irregulation was exited in the height. Also in accordance with paragraph 3.2.3 of Regulations of construction of buildings against earthquakes (2800 Fourth Edition), dynamic analysis method can be used for all buildings, but applying them for buildings not subject to Clause 2.2.3 is essential. So considering all mentioned issues, the frames considered in this study were analyzed, designed and applied, as Figures 1 and Figure 2 show the geometry and sections used in these frames.

\section{A. Vulnerability correlation No.1: Annual Frequency of Exceeding Demand - DM Hazard}

Here we want to derive a method based on displacement for calculating the probability of occurrence of limit conditions, as this issue is discussed in the following two sections:

- The first part: We obtain the possibility that the demand exceeds the specified value of $d$.

- The second part: The possibility that demand exceeds capacity.

In reality the second part is to obtain probability of limit states. These correlations are as follows:

$$
\begin{aligned}
& \text { LOGISTIC }: H_{D}(d)=H_{S a}\left(S a^{d}\right) \cdot e^{9 / 4 \cdot k^{2} / \pi^{2} \cdot\left(\beta_{D \mid s a} / b\right)^{2}} \\
& \text { LOG-NORMAL }: H_{D}(d)=H_{S a}\left(S a^{d}\right) \cdot e^{1 / 2 \cdot k^{2} \cdot\left(\beta_{D \mid a} / b\right)^{2}}
\end{aligned}
$$

Where:

$$
\begin{aligned}
& H_{S a}\left(S a^{d}\right)=k_{0}\left(\frac{d}{a}\right)^{(-k / b)} \\
& \beta_{\mathrm{D} \mid S a}=\sigma=\sqrt{\frac{\sum_{\mathrm{i}=1}^{\text {count }}\left(\mathrm{d}_{i_{\text {[modele }}}-\mathrm{d}_{i_{\text {\{recordil }}}\right)^{2}}{(\text { count }-1)}}
\end{aligned}
$$

In these correlations $\beta_{D \mid S a}$ is the logarithmic standard deviation of demand. This parameter is calculated in two ways, based on correlations 2 and 3. Based on the figures and tables, the values of structural vulnerability in the logistics method is lower than that of the log-normal approach and this difference is more clear in braced structures. Also in terms of numerical values, the braced structure showed more vulnerability, representing the higher vulnerability of the structure. In the case of showing the difference between the values obtained for structures, the correlations derived based on the SA, showed more realistic differences due to the dependence of these parameters to specifications and period of structure compared to PGA-based values.

\section{B. Vulnerability correlation (2): Annual Frequency of Exceeding a Limit State - the DM-Based Approach.}

So far, we obtained the possibility of passing a limiting case of a specified value. The next step is to calculate the probability of limit state variable from a certain threshold. The difference is that here, the threshold limit states can be a random variable. And now we want to obtain the probability occurrence of limit state, as the threshold of limit states is a variable, not a constant figure. These relationships are as follows:

LOGISTIC $: H_{L S}=H_{S a}\left(S^{\eta_{c}}\right) \cdot e^{9 / 4^{2} / k^{2} / \pi^{2} \cdot\left(\beta_{D \mid p a} / b\right)^{2}} \cdot e^{1 / 2 \cdot k^{2} \cdot\left(\beta_{c} / b\right)^{2}}$
LOG-NORMAL $: H_{L S}=H_{S a}\left(S a^{\eta_{c}}\right) \cdot e^{1 / 2^{2} \cdot k^{2} \cdot\left(\beta_{D \mid a} / b\right)^{2}} \cdot e^{1 / 2 \cdot k^{2} \cdot\left(\beta_{c} / b\right)^{2}}$

Where: 


$$
\begin{aligned}
& H_{S a}\left(S a^{\eta_{c}}\right)=k_{0}\left(\frac{\eta_{c}}{a}\right)^{(-k / b)} \\
& \beta_{c}=\sigma(\operatorname{Ln}(\text { Target }\{\mathrm{DM}\})) \\
& \eta_{c}=\text { median }(\text { Target }\{\mathrm{DM}\})
\end{aligned}
$$

Where $\beta_{c}$ is the logarithm of standard deviation of capacity based on the damage intensity of the structure and $\eta_{c}$ is the mean of capacity based on the damage intensity of the structure. This parameter has been calculated in two ways, based on correlations 4 and 5, respectively. Based on the figures and tables, the values of structural vulnerability in the logistics method was lower than that of log-normal and in the case of braced structures, the difference is more clear.

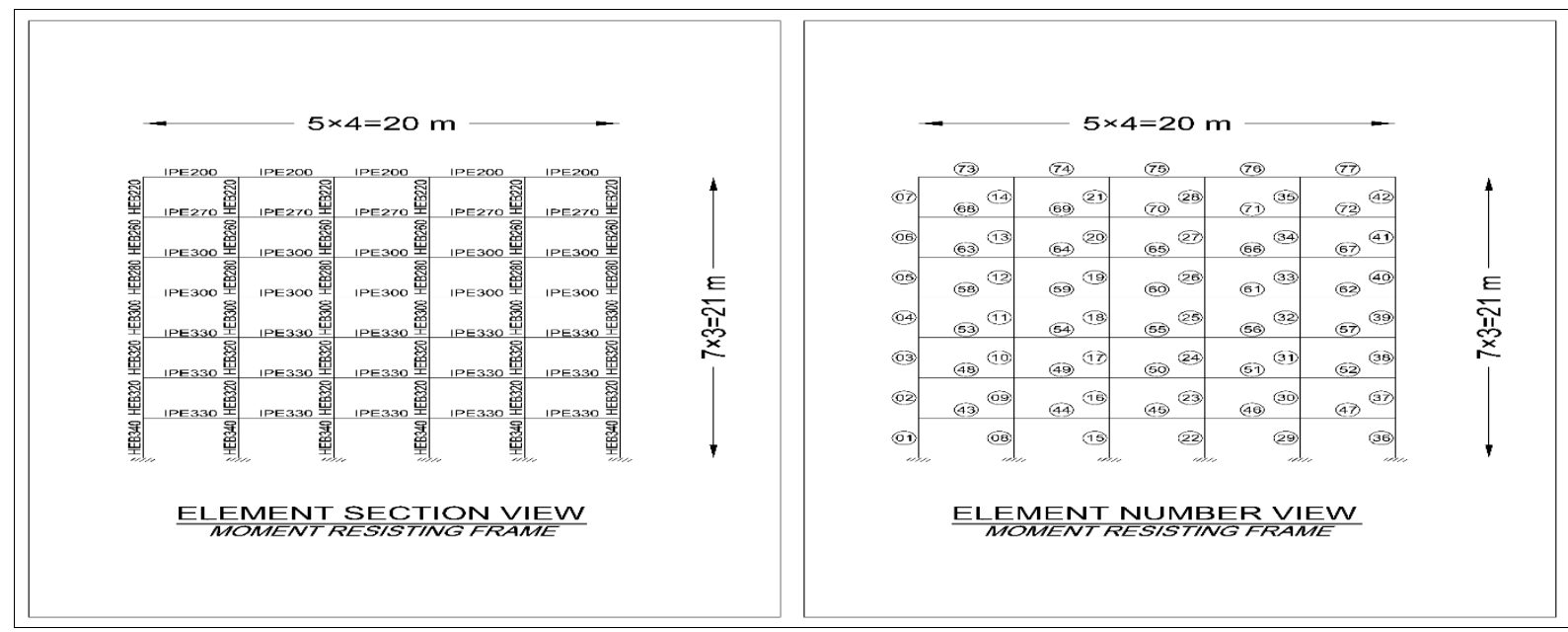

Fig. 1. The geometry and sections dedicated to mean steel moment frame



Fig. 2. Geometric properties and sections dedicated coaxial braced frame Steel (Crossed)

\section{Annual Frequency of Exceeding a Limit State - the IM-} Based Approach

In this section, we act completely similar to the previous section, except that in this section we want to calculate $\mathrm{H}_{\mathrm{LS}}$ with IM-based approach. These correlations are as follows:

$$
\begin{aligned}
& \text { LOGISTIC }: H_{L S}=H_{S a}\left(\eta_{S a, c}\right) \cdot e^{9 / 4^{\cdot} \cdot k^{2} / \pi^{2} \cdot \beta_{S a, c}{ }^{2}} \\
& \text { LOG-NORMAL: } H_{L S}=H_{S a}\left(\eta_{S a, c}\right) \cdot e^{1 / 2 \cdot k^{2} \cdot \beta_{S a, c}{ }^{2}}
\end{aligned}
$$

Where:

$$
\begin{aligned}
& H_{S a}\left(\eta_{S a, c}\right)=k_{0} \cdot \eta_{S a, c}^{-k} \\
& \beta_{S a, c}=\sigma(\operatorname{Ln}(\text { Target }\{\mathrm{IM}\})) \\
& \eta_{S a, c}=\operatorname{median}(\text { Target }\{\mathrm{IM}\})
\end{aligned}
$$

In these correlations, $\beta_{\mathrm{Sa}, \mathrm{c}}$ is the logarithm of standard deviation of capacity based on the ground motion intensity and $\eta_{S a, c}$ is the mean of intensity based on the ground motion intensity. This parameter is calculated in two ways, based on correlations 6 and 7. According to the findings, quantities of structural vulnerability in the logistics method are lower than that of the log-normal approach and this difference is more obvious in the braced structures. Also in terms of numerical 
values, braced structures represented more vulnerability that represents that the structure is more vulnerable. In the case of showing the difference of obtained values for the structures, due to the dependence of these parameters to the specifications and period of structures, the correlations obtained on the basis of SA showed more realistic values than PGA-based ones in Tables I-IV.

\section{Vulnerability correlation (4). Probability of Exceeding a DM Demand Value - DM Hazard}

In this section the possibility that demand exceeds a certain amount of structural damage intensity (threshold) is introduced as the risk of structural failure intensity. The correlations are as shown below:

LOGISTIC: $: \bar{H}_{D}(d)=\bar{H}_{S a}\left(S a^{d}\right) \cdot e^{9 / 4^{\cdot} \cdot k^{2} / \pi^{2} \cdot\left(\beta_{R D} / b\right)^{2}} \cdot e^{1 / 6^{2} \cdot k^{2} / b^{2} \cdot \beta_{U D}{ }^{2}}$

LOG-NORMAL: $\bar{H}_{D}(d)=\bar{H}_{S a}\left(S a^{d}\right) \cdot e^{1 / 2 \cdot k^{2} \cdot\left(\beta_{R D} / b\right)^{2}} \cdot e^{1 / 2 \cdot k^{2} / b^{2} \cdot \beta_{U D}{ }^{2}}$

where:

$$
\begin{aligned}
& \text { LOGISTIC: } \bar{H}_{S a}\left(\mathrm{Sa}^{d}\right)=k_{0} \cdot\left(\frac{d}{a}\right)^{-k / b} \cdot e^{\beta_{U H}{ }^{2} / 6} \\
& \text { LOG-NORMAL: } \bar{H}_{S a}\left(S a^{d}\right)=k_{0} \cdot\left(\frac{d}{a}\right)^{-k / b} \cdot e^{\beta_{U H}^{2} / 2} \\
& \beta_{R D}=\beta_{D \mid S a} \\
& \beta_{U D}=\frac{\beta_{R D}}{\sqrt{\{\text { count }\}}} \\
& \beta_{U H}=0.5
\end{aligned}
$$

In these correlations, $\beta_{U H}$ is in danger of risk curve. This parameter is calculated in two ways, based on correlations 8 and 9. According to the figures and tables, the values of structural vulnerability of structures in the logistics approach is lower than that of the log-normal method and the braced structures it represents the clearest difference. Also in terms of numerical values, braced structures represent more vulnerability of the structure. In the case of the difference between the values obtained for the structures, due to the dependence of this parameter to the specifications and period of the structures, the correlations derived on the basis of SA, PGA-based values showed more realistic differences.

\section{E. Vulnerability correlation (5). Annual Probability of Exceeding a Limit State}

In this section we want to determine the risk of Probability where the damage of structure exceeds the limit state (or the probability or occurrence of limit state or frequency of limit states) while facing the uncertainty (due to lack of knowledge and data). At the final step, we introduced the demand exceeds the specific value of structure damage intensity as the term of risk of structure damage intensity. Uncertainty was also considered for obtaining the risk of ground motion intensity and demand of structures damage intensity. Now, we want to determine the possibility of pass from demand of structures damage intensity from the capacity of structures damage intensity (which itself is an uncertain quantity). Similar to the previous section, capacity was considered as the random variable. The correlations are as shown below:

$$
\begin{aligned}
& \text { LOGISTIC }: \bar{H}_{L S}= \\
& \bar{H}_{S a}\left(S a^{\widehat{\eta}_{c}}\right) \cdot e^{9 / 4^{2} / \pi^{2} \cdot\left(\beta_{R D} / b\right)^{2}} \cdot e^{1 / 2 \cdot k^{2} / b^{2} \cdot \beta_{R C}{ }^{2}} \cdot e^{1 / 6^{k^{2}} / b^{2} \cdot\left(\beta_{U D}{ }^{2}+\beta_{U C}{ }^{2}\right)} \\
& \text { LOG-NORMAL: } \\
& \bar{H}_{L S}=\bar{H}_{S a}\left(S a^{\hat{\eta}_{c}}\right) \cdot e^{1 / 2 \cdot k^{2} / b^{2} \cdot\left(\beta_{R D}{ }^{2}+\beta_{U D}{ }^{2}\right)} \cdot e^{1 / 2 \cdot k^{2} / b^{2} \cdot\left(\beta_{R C}{ }^{2}+\beta_{U C}{ }^{2}\right)}
\end{aligned}
$$

Where:

$$
\begin{aligned}
& \bar{H}_{S a}\left(S a^{\widehat{\eta_{c}}}\right)=k_{0} \cdot\left(\widehat{\eta_{c}} / a\right)^{-k / b} \\
& \beta_{R C}=\beta_{C} \\
& \beta_{U C}=\frac{\beta_{R C}}{\sqrt{\{\text { count }\}}}
\end{aligned}
$$

This parameter has been calculated in two ways, based on correlations 10 and 11, respectively. Based on the figures and tables, the values of structural vulnerability in the logistics method were lower than that of the log-normal approach, and in the case of braced structures, the difference is more clear. Also in terms of numerical values, braced structures represented more vulnerability, representing that the structure is more vulnerable. In the case of showing the difference values obtained for the structures, due to the dependence of these parameters to the specifications and period of the structures, the correlations calculated on the basis of SA showed more realistic data than the PGA-based data.

\section{F. Vulnerability correlation (6). Annual Probability of Exceeding a Limit State - the IM-Based Approach}

The annual probability of passing the limiting state was obtained in previous sections by using IM method. But there we only considered the uncertainties caused by changes of one record to another record for demand and capacity. In this section we want to apply the same method to obtain the probability of limit state by considering the uncertainties caused by lack of knowledge and data. These correlations are as follows :

$$
\begin{aligned}
& \text { LOGISTIC: }: \bar{H}_{L S}=\bar{H}_{S a}\left(S a^{\widehat{\eta_{c}}}\right) \cdot e^{9 / 4^{k^{2}} / \pi^{2} \cdot\left(\beta_{R S a, C}\right)^{2}} \cdot e^{1 / 6 \cdot\left(k^{2} \cdot \beta_{U S a, C^{2}}\right)} \\
& \text { LOG-NORMAL: } \bar{H}_{L S}=\bar{H}_{S a}\left(S a^{\widehat{\eta_{c}}}\right) \cdot e^{1 / 2^{2} \cdot k^{2} / b^{2} \cdot\left(\beta_{R S a, C^{2}}+\beta_{U S a, C^{2}}\right)}
\end{aligned}
$$

Where:

$$
\begin{aligned}
& \bar{H}_{S a}\left(S a^{\widehat{\eta}_{c}}\right)=k_{0} \cdot\left(\widehat{\eta_{c}} / a\right)^{-k / b} \\
& \beta_{R S a, C}=\beta_{S a, c} \\
& \beta_{U S a, C}=\frac{\beta_{R S a, C}}{\sqrt{\{\text { count }\}}}
\end{aligned}
$$

This parameter has been calculated in two ways, based on correlations 12 and 13, respectively. Based on the findings, the values of structural vulnerability in the logistics method were 
lower than that of the log-normal approach, and in the case of braced structures, the difference is clearer. Also in the case of numerical, th braced structure showed more vulnerability, reflecting its more vulnerability to damage. In the case of showing the difference values obtained for the structures, due to the dependence of these parameters to the specifications and period of the structures, the correlations calculated on the basis of SA showed more realistic data than the PGA-based data in Tables V-VIII.

TABLE I. VULNERABILITY CORRELATION (3), BASED ON THE DIP.-PGA FOR TWO STUDIED FRAMES

\begin{tabular}{|c|c|c|c|}
\hline $\begin{array}{c}H_{L S} \\
\{\text { DISP.-PGA } \\
\text { Logistic-[MF] }\end{array}$ & $\begin{array}{c}H_{L S} \\
\{\text { DISP.-PGA }\} \\
\text { Logistic-[BF] }\end{array}$ & $\begin{array}{c}H_{L S} \\
\{\text { DISP.-PGA }\} \\
\text { Log Normal-[MF] }\end{array}$ & $\begin{array}{c}H_{L S} \\
\{\text { DISP.-PGA }\} \\
\text { Log Normal-[BF] }\end{array}$ \\
\hline 0.000285544 & 0.000904713 & 0.000409753 & 0.001152174 \\
\hline
\end{tabular}

TABLE II. VULNERABILITY CORRELATION (3), BASED ON THE DISP.-SA FOR TWO STUDIED FRAMES

\begin{tabular}{|c|c|c|c|}
\hline $\begin{array}{c}H_{L S} \\
\{\text { DISP.-SA\} } \\
\text { Logistic-[MF] }\end{array}$ & $\begin{array}{c}\quad H_{L S} \\
\{\text { DISP.-SA }\} \\
\text { Logistic- }[\mathrm{BF}]\end{array}$ & $\begin{array}{c}H_{L S} \\
\{\text { DISP.-SA\} } \\
\text { Log Normal- } \\
{[\mathrm{MF}]} \\
\end{array}$ & $\begin{array}{c}H_{L S} \\
\{\text { DISP.-SA\} } \\
\text { Log Normal- } \\
{[\mathrm{BF}]} \\
\end{array}$ \\
\hline 0.000389395 & 0.000593656 & 0.000662878 & 0.000781767 \\
\hline
\end{tabular}

TABLE III. VULNERABILITY CORRELATION (3), BASED ON THE DRIFT-PGA FOR TWO STUDIED FRAMES

\begin{tabular}{|l|c|c|c|}
\hline$H_{L S}$ & $H_{L S}$ & $H_{L S}$ & $H_{L S}$ \\
$\begin{array}{c}\text { \{DRIFT-PGA } \\
\text { Logistic-[MF] }\end{array}$ & $\begin{array}{c}\text { \{DRIFT-PGA } \\
\text { Logistic-[BF] }\end{array}$ & $\begin{array}{c}\text { \{DRIFT-PGA } \\
\text { Log Normal- } \\
\text { [MF] }\end{array}$ & $\begin{array}{c}\text { \{DRIFT-PGA } \\
\text { Log Normal- } \\
\text { [BF] }\end{array}$ \\
\hline 0.000283478 & 0.001766809 & 0.000393283 & 0.002131271 \\
\hline
\end{tabular}

TABLE IV. VULNERABILITY CORRELATION (3), BASED ON THE DRIFT-SA FOR TWO STUDIED FRAMES

\begin{tabular}{|c|c|c|c|}
\hline$H_{L S}$ & $H_{L S}$ & $H_{L S}$ & $H_{L S}$ \\
$\{$ DRIFT-SA & $\{$ DRIFT-SA & \{DRIFT-SA & Log Normal- \\
Logistic-[MF] & Logistic-[BF] & Log Normal- \\
& {$[\mathrm{MF}]$} & {$[\mathrm{BF}]$} \\
\hline 0.000300858 & 0.000978815 & 0.000501526 & 0.001393139 \\
\hline
\end{tabular}

TABLE V. VULNERABILITY CORRELATION (6), BASED ON THE DISP.-PGA FOR TWO STUDIED FRAMES

\begin{tabular}{|c|c|c|c|}
\hline$H_{L S}$ & $H_{L S}$ & $H_{L S}$ & $H_{L S}$ \\
$\{$ DISP.-PGA & $\{$ DISP.-PGA & $\{$ DISP.-PGA & $\{$ DISP.-PGA \\
Logistic-[MF] & Logistic-[BF] & $\begin{array}{c}\text { Log Normal- } \\
\text { Log }]\end{array}$ & {$[\mathrm{MF}]$} \\
\hline 0.000418844 & 0.000413495 & 0.000331439 & 0.00042035 \\
\hline
\end{tabular}

TABLE VI. VULNERABILITY CORRELATION (6), BASED ON THE DISP.-SA FOR TWO STUDIED FRAMES

\begin{tabular}{|c|c|c|c|}
\hline$H_{L S}$ & $H_{L S}$ & $H_{L S}$ & $H_{L S}$ \\
$\begin{array}{c}\text { \{DISP.-SA } \\
\text { Logistic-[MF] }\end{array}$ & $\begin{array}{c}\text { \{DISP.-SA } \\
\text { Logistic-[BF] }\end{array}$ & $\begin{array}{c}\text { Log Normal- } \\
\text { [MF] }\end{array}$ & $\begin{array}{c}\text { [DISP.-SA } \\
\text { Log Normal- } \\
{[\mathrm{BF}]}\end{array}$ \\
\hline 0.000404206 & 0.000565317 & 0.000296043 & 0.000482789 \\
\hline
\end{tabular}

TABLE VII. VULNERABILITY CORRELATION (6), BASED ON THE DRIFT-PGA FOR TWO STUDIED FRAMES

\begin{tabular}{|c|c|c|c|}
\hline $\begin{array}{c}H_{L S} \\
\{\text { DRIFT-PGA\} } \\
\text { Logistic-[MF] }\end{array}$ & $\begin{array}{c}H_{L S} \\
\{\text { DRIFT-PGA } \\
\text { Logistic-[BF] }\end{array}$ & $\begin{array}{c}H_{L S} \\
\{\text { DRIFT-PGA } \\
\text { Log Normal- } \\
{[\mathrm{MF}]}\end{array}$ & $\begin{array}{c}H_{L S} \\
\{\text { DRIFT-PGA\} } \\
\text { Log Normal- } \\
{[\mathrm{BF}]}\end{array}$ \\
\hline 0.000409736 & 0.000650206 & 0.000331405 & 0.000658552 \\
\hline
\end{tabular}

TABLE VIII. VULNERABILITY CORRELATION (6), BASED ON THE DRIFT-SA FOR TWO STUDIED FRAMES

\begin{tabular}{|c|c|c|c|}
\hline$H_{L S}$ & $H_{L S}$ & $H_{L S}$ & $H_{L S}$ \\
$\{$ DRIFT-SA & $\{$ DRIFT-SA & $\{$ DRIFT-SA & Log Normal- \\
Logistic-[MF] & Logistic-[BF] & $\begin{array}{c}\text { Log Normal- } \\
\text { [MF] }\end{array}$ \\
\hline 0.000362407 & 0.000715243 & 0.000268709 & 0.000584209 \\
\hline
\end{tabular}

\section{CONCLUSION}

By reviewing the figures and tables related to vulnerability, it can be concluded that the mean steel moment frame structures showed less vulnerability than steel coaxial braced frame structures (cross). In this way, depending on the type of IM and DM parameters, between $20 \%$ to $90 \%$ of vulnerability values of steel moment frames were less than coaxial braced frame structures (cross). The greatest difference was observed when using displacement as a component of structural damage and peak of ground acceleration as the component of ground motion intensity. In the case of vulnerability correlations of logistic and log-normal methods, it is concluded that correlations of log-normal represented more conservative values than the logistics ones. In the same way, depending on the type of structure and parameters of IM and DM, vulnerability values were about $5 \%$ to $20 \%$ lower than that of the logistic method.

This means that the designs based on the logistics methodsby assumption of loading and similar site and structure- would calculate lighter and more cost-effective sections than the lognormal method. In the coaxial braced frame, difference between logistic and log-normal methods are more evident than the moment frame. The most important reason for this case can be found in the risk curves. Based on these curves, the higher period of the structure, the lower probability of exceeding a certain intensity. So the moment frame structures with higher period, provides lower risk values $\left(\mathrm{k}_{0}\right.$ and $\left.\mathrm{k}\right)$. Since the majority of logistic and log-normal differences can be seen in the coefficients associated with these two parameters, thereby the moment frame structure with a less period (due to the lower effectiveness by these parameters), shows less difference between the two correlations. While examining the methods in which the ground motion parameters (IM) is the type of peak of ground motion PGA, difference of structures is less evident. The reason is that the values of the probability of the event obtained from the risk curve were related to the peak of ground motion independent of the structure period (PGA is one of the seismic characteristics of the ground independent from type of structure and its period), as gives the constant value for both types of the structures. 


\section{REFERENCES}

[1] N. Luco, C. Cornell, "Effects of connection fractures on SMRF seismic drift demands", ASCE Journal of Structural Engineering, Vol. 1, No. 1, pp. 127-136, 2000

[2] N. Luco, C. Cornell, "Effects of random connection fractures on demands and reliability for a 3-story pre-Northridge SMRF structure", Proceedings of the 6th U.S. National Conference on Earthquake Engineering, paper 244, Vol. 1, No. 2, pp. 1-12, 1998

[3] P. Bazzurro, C. Cornell, "Seismic hazard analysis for non-linear structures. I: Methodology", ASCE Journal of Structural Engineering, Vol. 1, No. 7, pp. 332-3344, 1994

[4] P. Bazzurro, C. Cornell, "Seismic hazard analysis for non-linear structures. II: Applications", ASCE Journal of Structural Engineering, Vol. 1, No. 7, pp. 3345-3365, 1994

[5] S. Yun, R. Hamburger, C. Cornell, D. Foutch, "Seismic performance for steel moment frames", ASCE Journal of Structural Engineering, Vol. 1, No. 8, pp. 20-25, 2002

[6] S. Mehanny, G. Deierlein, Modeling and assessment of seismic performance of composite frames with reinforced concrete columns and steel beams, The John A. Blume Earthquake Engineering Center, Stanford University, Report No. 135, 2000

[7] D. Dubina, A. Ciutina, A. Stratan, F. Dinu, "Ductility demand for semi-rigid joint frames", Moment Resistant Connections Of Steel Frames In Seismic Areas, Vol. 6, No. 7, pp. 371-408, 2000

[8] G. De Matteis, R. Landolfo, D. Dubina, A. Stratan, "Influence of the structural typology on the seismic performance of steel framed buildings", Moment Resistant Connections Of Steel Frames In Seismic Areas, Vol. 1, No. 7, pp. 513-538, 2002

[9] A. Nassar, H. Krawinkler, "Seismic demands for SDOF and MDOF systems", The John A. Blume Earthquake Engineering Center, Stanford University, Stanford, Vol. 8, No. 7. pp. 1991

[10] I. Psycharis, D. Papastamatiou, A. Alexandris, "Parametric investigation of the stability of classical comlumns under harmonic and earthquake excitations", Earthquake Engineering and Structural Dynamics, Vol. 8, No. 7, pp. 1093-1109, 2000

[11] C. A. Cornell, D. Vamvatsikos, F. Jalayer, N. Luco, "Seismic reliability of steel frames", Proc., 9th IFIP WG 7.5 Working Conf. on
Reliability and Optimization of Structural Systems, Vol. 8, No. 9, pp. 30-35, 2000

[12] FEMA, "350: Recommended seismic design criteria for new steel moment-frame buildings", Federal Emergency Management Agency, Washington DC, Vol. 5, No. 4, pp. 15-20, 2000

[13] G. G. Deierlein, H. Krawinkler, C. A. Cornell, "A framework for performance-based earthquake engineering", Pacific conference on earthquake engineering, 2003

[14] H. U. Koyluoglu, S. R. Nielsen, J. Abbott, A. S. Cahmak, "Local and modal damage indicators for RC frames subject to earthquakes", Journal of Engineering Mechanics, Vol. 124, No. 12, pp. 1371-1379, 1998

[15] P. S. Skjaerbaek, S. R. K. Nielsen, A. S. Cakma, "Assessment of damage in seismically excited rc-structures from a single measured response", Proc. of the 14th International Modal Analysis Conference, Vol. 1, No. 2, pp. 133-139, 1996

[16] F. Paulet-Crainiceanu, Active Control Approach for Long Span Bridge Responses to Strong Earthquakes, Ph. D. Thesis, Yokohama National University, Yokohama, 1997

[17] A. Madan, A. M. Reinhorn, J. B. Mander, R. E. Valles. "Modeling of masonry infill panels for structural analysis", Journal of Structural Engineering, Vol. 123, No. 10, pp. 1295-1302, 1997

[18] Y. J. Park, A. H. S. Ang, "Mechanistic seismic damage model for reinforced concrete", Journal of Structural Engineering, Vol. 111, No. 4, pp. 722-739, 1985

[19] A. Teran-Gilmore, "Energy concepts and damage indices", Proceedings of the Symposium CUREe-EERC, Vol. 1, No. 4, pp. 133140, 1997

[20] R. Razani, K. L. Lee, "The engineering aspects of the Qir earthquake of 10 April 1972 in southern Iran", National Academy of Science, Washington. Vol. 1, No. 1, pp. 102-105, 1973

[21] F. Hamedi, M. Tehrani Zadeh, Amir Kabir University Magazine, Vol. 50, Vol. 1, No. 1, pp. 307, 2002

[22] M. A. Shayanfar, M. Angouti. "The study of seismic vulnerability of gravity load designed reinforced concrete frame", Journal of School of Engineering, Vol. 13, No. 2, pp. 45-58, 2001

[23] T. Angotti, "Playing politics with disaster", International Journal of Urban and Regional Research, Vol. 1, No. 4, pp. 327-331, 1977 